\title{
Is ENSO a cycle or a series of events?
}

\author{
William S. Kessler \\ NOAA/Pacific Marine Environmental Laboratory, Seattle, Washington, USA
}

Received 19 July 2002; revised 1 October 2002; accepted 2 October 2002; published 12 December 2002.

[1] After early ideas that saw El Niños as isolated events, the advent of coupled models brought the conception of ENSO as a cycle in which each phase led to the next in a self-sustained oscillation. Twenty-two years of observations that represent the El Niño and La Niña peaks (east Pacific SST) and the memory of the system (zonal mean warm water volume) suggest a distinct break in the cycle, in which the coupled system is able to remain in a weak La Niña state for up to two years, so that memory of previous influences would be lost. Similarly, while the amplitude of anomalies persists from the onset of a warm event through its termination, there is no such persistence across the La Niña break. These observations suggest that El Niños are in fact event-like disturbances to a stable basic state, requiring an initiating impulse not contained in the dynamics of the cycle itself. INDEX TERMS: 4522 Oceanography: Physical: El Niño; 1620 Global Change: Climate dynamics (3309); 4504 Oceanography: Physical: Air/sea interactions (0312). Citation: Kessler, W. S., Is ENSO a cycle or a series of events?, Geophys. Res. Lett., 29(23), 2125, doi:10.1029/2002GL015924, 2002.

\section{Background}

[2] When El Niño was first recognized as a basin-scale event, it was thought of as a disturbance to normal conditions that lasted for a time, then ended. Bjerknes [1969] realized that both warm and cool states of the equatorial Pacific could be maintained by positive feedbacks, for example cool SST in the east fosters a strong Walker circulation that reinforces the SST pattern through upwelling and surface fluxes, but he did not know how these states could be reversed. Wyrtki $[1975 ; 1985]$ showed that El Niño events were preceded by high sea level in the west, and hypothesized that the event ended when this "buildup" was drained eastward, then poleward along the American coast. In Wyrtki's scheme, the next event could not occur until another buildup had taken place, but otherwise there was no necessary connection between one event and the next.

[3] With the advent of simple and intermediate coupled models in the 1980s, it was realized that a cyclic phenomenon was possible, with lagged negative feedback provided by the reflection of Rossby waves generated during one phase of the cycle returning along the equator to initiate a reversal of the phase [McCreary, 1983; Cane and Zebiak, 1985; Battisti and Hirst, 1989]. These ideas have become known as the "delayed oscillator" paradigm [Suarez and Schopf, 1988; Schopf and Suarez, 1988]. Such models have gained credibility because they demonstrate forecast skill comparable to that of more sophisticated models [Latif et

This paper is not subject to U.S. copyright.

Published in 2002 by the American Geophysical Union. al., 1998] and because the properties of the coupled climate of the Pacific can be easily explored in the parameter space of these dynamical systems (see Neelin et al. [1998] for a review). The cyclic paradigm exemplified by the intermediate models has become the widely accepted description of ENSO. A variety of observational [Li and Clarke, 1994; Kessler and McPhaden, 1995; Weisberg and Wang, 1997; McPhaden, 1999; Harrison and Vecchi, 1999; Zhang and Rothstein, 2000; Larkin and Harrison, 2002] and coupled GCM studies [Nagai et al., 1995; Schneider et al., 1997; Knutson et al., 1997; Vimont et al., 2002] have attempted to confirm the delayed oscillator paradigm with mixed success; in particular some observational studies have pointed out that while the termination of El Niños has occurred consistent with the cyclic nature of delayed oscillator physics, their initiation is less obvious [Kessler and McPhaden, 1995]. This asymmetry is also seen in the fact that recent El Niños have seemed to come out of nowhere, not forecast until shortly before the anomalies become obvious, but then evolve with a fairly repeatable sequence in which warm east Pacific SSTs last up to a year before fading.

[4] A recent simple model brings together many of these previous ideas by proposing that the phase transition mechanism is the recharge and discharge of warm water from the upper layer of the equatorial Pacific [Jin, 1997]. Anomalous thermocline tilts during El Niño and La Niña produce anomalous meridional geostrophic transports: poleward during the flattened thermocline of El Niño and equatorward during the enhanced slope of La Niña. These transports shallow or deepen the equatorial thermocline as a whole, and this slow vertical motion overcomes the Bjerknes positive feedbacks that would otherwise sustain the anomalies. For example, meridional divergence during El Niño lifts the thermocline and thereby cools SST, leading to easterly wind anomalies. Thus Wyrtki's buildup and draining hypothesis is enlarged to be more than just an isolated event of one sign, but instead explicitly leads to the opposite phase, with the memory of the system in the zonal mean thermocline depth. Moreover, the mechanism is seen to work equally well (in Jin's simple model context) for the transition from La Niña to recharge to El Niño. Jin's paradigm is more general than the delayed oscillator in not relying explicitly on equatorial wave propagation (in fact Jin proposes that the zonal thermocline slope can be considered to be in equilibrium balance with the zonal wind) but the mechanism is fundamentally the same, in either case representing the slow (relative to the 2-3 month basin-crossing time of Kelvin waves) adjustment of the equatorial ocean to wind anomalies. In the delayed oscillator, Rossby waves and their reflections are the means by which mass is added to or removed from the equatorial upper layer. An advantage of the Jin formulation is that it points to a convenient set of variables that can be evaluated 
from observations. Zonal mean warm water volume (essentially Wyrtki's buildup) should be in quadrature with east Pacific SST or central Pacific zonal wind, with positive and negative peaks of warm water volume anomalies producing the transition from El Niño to La Niña and back. These variables serve to evaluate the delayed oscillator as well, which would produce the same phase relationship. Meinen and McPhaden [2000] examined 18 years of surface and subsurface temperature data, and found that the phase sequence predicted by Jin [1997] is in fact observed. They noted, however, that the amplitudes moving from one phase of the cycle to another are asymmetric, with a given amplitude of recharge being associated with a larger subsequent El Niño SST anomaly than is the case for the discharge-La Niña phase of the cycle. The purpose of the present work is to consider what this asymmetry implies about the cyclic nature of the ENSO phenomenon.

\section{Data and Processing}

[5] Monthly values of SST anomalies (relative to the 1971-2000 average annual cycle) in the Nino3 region $\left(5^{\circ} \mathrm{N}\right.$ to $5^{\circ} \mathrm{S}, 150^{\circ} \mathrm{W}$ to $\left.90^{\circ} \mathrm{W}\right)$ were obtained from the web site of the NOAA Climate Prediction Center (http:// www.cpc.ncep.noaa.gov/data/indices/). Warm water volume (WWV) was estimated as the mean depth of the $20^{\circ} \mathrm{C}$ isotherm $(\mathrm{Z} 20)$ in the region $5^{\circ} \mathrm{N}-5^{\circ} \mathrm{S}, 130^{\circ} \mathrm{E}-80^{\circ} \mathrm{W}$, from the Australian Bureau of Meteorology Research Centre (BMRC) gridded subsurface temperatures [Smith, 1995a, 1995b]. This data set is an optimal interpolation on a $1^{\circ}$ latitude by $2^{\circ}$ longitude grid, with 14 depth levels, based on XBT and hydrographic profiles and time series from the Tropical Atmosphere-Ocean (TAO) buoy array. It spans the period January 1980 through August 2002. In the equatorial region of present interest, most of the data comes from the TAO buoys. Z20 was found by linear interpolation in depth, and the average annual cycle over 1980 through 2001 was removed. Both SST and Z20 anomalies were filtered with a 7-month running mean, so comparable time series were available from April 1980 through May 2002. Hereafter, "SST" will refer to the Nino3 region average, and "WWV" will refer to zonally and meridionally averaged Z20, both quantities being filtered anomalies as described above.

\section{Observed Time Series}

[6] There were six El Niño events in the 22 years studied, with peak SST anomalies in December 1982,

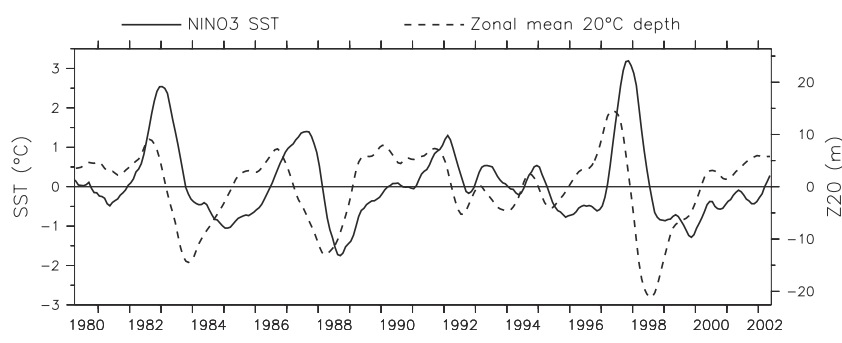

Figure 1. Time series of Niño3 SST (solid, ${ }^{\circ} \mathrm{C}$, scale at left) and zonal mean $20^{\circ} \mathrm{C}$ depth (dashed, meters, scale at right) anomalies from the average annual cycle, filtered with a 7-month running mean. The axes are scaled so that each time series has equal variance.

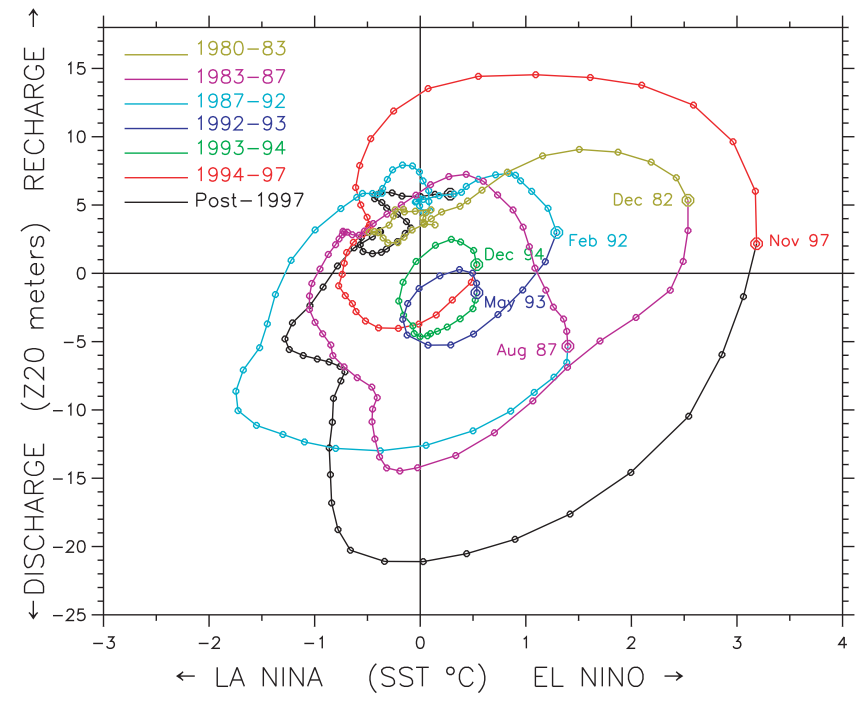

Figure 2. Phase orbits of the two time series in Figure 1. SST $\left({ }^{\circ} \mathrm{C}\right)$ is plotted along the abscissa, and zonal mean $20^{\circ} \mathrm{C}$ depth $(\mathrm{m})$ along the ordinate, with the scales chosen so that a given distance in either direction represents an equal fraction of variance. Small dots are drawn at the center of each month. The line color changes at the peak of each El Niño SST maximum, which is also shown as a large dot and its date is labeled. The final point is May 2002, noted with a large black dot.

August 1987, February 1992, May 1993, December 1994 and November 1997 (Figure 1). The events of 1993 and 1994-95 were exceptional in being weaker in both WWV and SST anomalies, and in being much more short-lived. With the 7-month running mean filter used here, these two short events are barely resolved. However, throughout the time series, SST and WWV are seen to be roughly in quadrature, in the sequence: recharge, El Niño, discharge, La Niña. They are highly lag-correlated, with maximum correlations above \pm 0.7 at lags of about \pm 9 months. Plotting a phase diagram of the two time series against each other shows the quadrature relationship in the nearcircular orbits (Figure 2). There is quite apparently a marked persistence of amplitude for part of the cycle: a large recharge predicts a subsequent large El Niño SST anomaly, and then a large discharge. Comparing the amplitude at each time with that one-quarter cycle later shows correlations significant at the 95\% level (about 0.7 for the six cycles in Figure 2) from recharge through El Niño to discharge. We can speculate that some of the prediction skill demonstrated by forecast models is due to the relatively steady orbital motion and persistent amplitude over 8 to 12 months during the onset and peak phases of El Niño. On the other hand, there is little such persistence from the discharge phase to La Niña, and virtually no connection between the amplitude of La Nina anomalies and those of the subsequent recharge or El Niño. For example, the values and preceding development of SST and WWV were alike in April 1982, August 1986, May 1991 (and also in May 2002) (Figure 2), but the El Niños that emerged in subsequent months were very different. Meinen and McPhaden [2000] noted a similar difference in finding that the regression slope of 
WWV against SST was much larger for positive anomalies than for negative.

[7] It is also clear from the phase orbits (Figure 2) that the cycle moves steadily through three-quarters of the cycle, from late in the recharge phase through El Niño to discharge to La Niña, then pauses in the upper left quadrant of Figure 2 , in the state of weak La Niña, weak recharge. The orbits meander in this quadrant for many months. Almost $40 \%$ of the cycle time is spent in less than $25 \%$ of the cycle. Everywhere except in this quadrant (and very slightly into the upper right quadrant), the orbital motion is strictly clockwise. The average time from peak recharge to peak discharge (what would be called "an El Niño event" in the Wyrtki scenario) averaged 12.8 months, and was fairly consistent among the six events except for the brief El Niño of 1994-95 (the RMS among the six El Niños was 3.3 months). On the other hand, the time between discharge through La Niña to recharge was generally much longer and also highly variable, ranging from 6 to 42 months (and it has been 46 months since the peak discharge in 1998 until May 2002). Clarke and $\mathrm{Li}$ [1995] found a similar distinction based on the Southern Oscillation Index for a much longer period.

[8] This behavior can be seen in the original time series (Figure 1), as the pauses before the peak recharge that occurred in each of the large El Niño sequences (the weak and short-lived events of 1993 and 1994-95 are exceptions that cannot be tested given the 7-month running mean that has been applied to these time series). Typically in these pauses the SST anomalies are weakly negative and the warm water volume weakly positive (that is, in the upper left quadrant of Figure 2), and both time series remain relatively constant. This pausing is seen in 1980-81, 1985, 1989-90, briefly in mid-1996, and during 2000 through 2001. It has no discernible relation to the amplitude of previous or subsequent phases, and lasts an irregular amount of time, up to two years. Although some recharging is observed even years before the El Niños (e.g. 1980, 1989 and 2001), shortly before the warm event begins there is a surge of WWV, reaching its maximum after the SST has already warmed somewhat, after which the next three phases follow relatively swiftly. In the time series (Figure $1)$, this surge is seen as the abrupt increase of WWV as east Pacific SST is beginning to rise. In the phase diagram (Figure 2), it is notable in that the orbit emerges relatively abruptly from its pause in the upper left quadrant with positive anomalies of both WWV and SST increasing simultaneously for several months, leading to peak SST warming within a year. This behavior is seen for all four of the large El Niños since 1980.

\section{Discussion}

[9] The phase relations between warm water volume and east Pacific SST agree with the findings of Meinen and McPhaden [2000] that the observed ENSO sequence passes through the series of phases described by Jin [1997] and compatible with the delayed oscillator; however, two asymmetries are found as robust features of all four large events. First, the observed evolution pauses for up to two years in the weakly-recharged, weak-La Niña state, while moving relatively swiftly and steadily through the other phases.
Second, while there is reasonable persistence of amplitude through the phases of recharge to El Niño to discharge, this is not the case for the evolution leading up to the onset of warm events. Both of these suggest a break in the cycle preceding the onset of a warm event. Neither of these is consistent with the idea that ENSO is an at least partly selfsustained cycle in which each phase provides the impetus to evolve to the next (we are not envisioning a perfectly regular cycle, but that the memory of the previous phase is a central part of the evolution). In either the delayed oscillator or the Jin paradigm, each peak contains the seeds of its own demise (through meridional transport in the Jin formulation, or through Rossby wave generation and reflection in the delayed oscillator). That transition mechanism appears well borne out for the termination of the warm events, but not for the cold, as the Pacific climate system appears perfectly capable of sitting in the weak recharge state for periods long enough that any memory would be lost. The recharge due to meridional convergence during La Niña does not appear sufficient to produce the transition to a warm event on its own (or equivalently, the downwelling Rossby waves generated during La Niña do not lead to the coupled changes on the equator that generate an El Niño). In fact the principal recharge occurs well after the peak La Niña has concluded, and appears better described as part of an initiating sequence separate from the previous La Niña. In 1982, 1986 and 1997, WWV increased suddenly just before the El Niño began (Figure 1), in conflict with the idea that the recharge is the result of a slow adjustment to La Niña winds.

[10] The observations are consistent with a picture in which a warm event sequence leaves the system in a cool state with near-normal or slightly increased warm water volume, and this state can persist for years, losing memory of previous conditions. Initiation of a new sequence occurs with an increase of both warm water volume and SST (Meinen and McPhaden [2001] suggested that this late surge came from the west). Coupled feedbacks (deep thermocline contributes to warming SST, which fosters westerly wind anomalies) reinforce the growing El Niño, which is terminated 6-9 months after its peak by the lifting thermocline due to the slow oceanic adjustment to westerly wind anomalies. This is similar to Wyrtki's scenario, with the significant difference that the draining occurs in midbasin, not along the eastern boundary as he thought, which means that the event can be more confined to the tropics.

[11] The overall evolution of ENSO during the past two decades appears more consistent with the idea that the basic state is stable and warm events are produced by stochastic forcing external to the cycle itself, rather than as growing modes in an unstable dynamical system [Penland and Sardeshmukh, 1995; Thompson and Battisti, 2001]. The initiating process remains unknown, but seems independent of previous conditions, contrary to the Jin [1997] or delayed oscillator hypotheses. In this respect, the brief events of 1993 and 1994-95 imply that given the right impetus, a weak warm event can occur even without a substantial recharge. The fact that the initial emergence from the long pause has usually occurred in the first months of the year (January 1982, July 1986, January 1991 and March 1997) suggests either an increased sensitivity to perturbation at this time (the warmest point of the equatorial annual cycle) 
or an increase of suitable perturbations (for example the annual maximum of MJO activity in the Pacific (see Figure 11 of Kessler et al. [1995]), or the influence of boreal winter mid-latitude variability [Vimont et al., 2002]).

[12] It has been argued [Mantua and Battisti, 1994] that a sequence of unconnected events as described here can still be considered consistent with delayed oscillator physics, since the termination of individual El Niños still occurs as a consequence of waves generated during the height of the warm event. In this case the delayed oscillator is reduced to adding mechanistic detail to Wyrtki's [1975] picture, and loses most of its interpretive power, which lies in the concept of an oscillator with the memory of the system persisting across events. The intermediate coupled models have raised the possibility of a cyclic ENSO, and the resolution of this question should not be sidestepped.

[13] Acknowledgments. I thank George Philander for inviting me to an ENSO workshop in Trieste that spurred the speculations that led to this work. Dr Neville Smith kindly provided the BMRC subsurface temperature data set.

\section{References}

Battisti, D. S., and A. C. Hirst, Interannual variability in the tropical oceanatmosphere system: Influence of the basic state, ocean geometry and nonlinearity, J. Atmos. Sci., 46, 1687-1712, 1989.

Cane, M. A., and S. E. Zebiak, A theory for El Niño and the Southern Oscillation, Science, 228, 1084-1087, 1985.

Clarke, A. J., and B. Li, On the timing of warm and cold El Niño-Southern Oscillation events, J. Climate, 8, 2571-2574, 1995.

Harrison, D. E., and G. A. Vecchi, On the termination of El Niño, Geophys. Res. Lett., 26, 1593-1596, 1999.

Jin, F.-F., An equatorial ocean recharge paradigm for ENSO. Part I: Conceptual model, J. Atmos. Sci., 54, 811-829, 1997.

Kessler, W. S., and M. J. McPhaden, Oceanic equatorial waves and the 1991-1993 El Niño, J. Climate., 8, 1757-1774, 1995.

Kessler, W. S., M. J. McPhaden, and K. M. Weickmann, Forcing of intraseasonal Kelvin waves in the equatorial Pacific, J. Geophys. Res., 100, $10613-10631,1995$.

Knutson, T. R., S. Manabe, and D. F. Gu, Simulated ENSO in a global coupled ocean-atmosphere model: Multidecadal amplitude modulation and $\mathrm{CO}_{2}$ sensitivity, J. Climate, 10, 138-161, 1997.

Larkin, N. K., and D. E. Harrison, ENSO warm (El Niño) and cold (La Niña) event life cycles: Ocean surface anomaly patterns, their symmetries, asymmetries and implications, J. Climate, 15, 1118-1140, 2002.

Latif, M., D. Anderson, T. Barnett, M. Cane, R. Kleeman, A. Leetmaa, J. O'Brien, A. Rosati, and E. Schneider, A review of the predictability and prediction of ENSO, J. Geophys. Res., 103, 14375-14393, 1998

Li, B., and A. J. Clarke, An examination of some ENSO mechanisms using interannual sea level at the eastern and western equatorial boundaries and the zonally averaged equatorial wind, J. Phys. Oceanogr., 24, 681-690, 1994.

Mantua, N. J., and D. S. Battisti, Evidence for the delayed oscillator mechanism for ENSO: The "observed" oceanic Kelvin mode in the far western Pacific, J. Phys. Oceanogr., 24, 691-699, 1994.

McCreary, J. P., A model of tropical ocean-atmosphere interaction, Mon. Weather Rev., 111, 370-387, 1983.

McPhaden, M. J., Genesis and evolution of the 1997-98 El Niño, Science, 283, 950-954, 1999.

Meinen, C. S., and M. J. McPhaden, Observations of warm water volume changes in the equatorial Pacific and their relationship to El Niño and La Niña, J. Climate, 13, 3551-3559, 2000.

Meinen, C. S., and M. J. McPhaden, Interannual variability in warm water volume tramsport in the equitorial Pacific during 1993-99, J. Phys. Oceanogr, 31, 1324-1345, 1993.

Nagai, T., Y. Kitamura, M. Endoh, and T. Tokioka, Coupled atmosphere ocean model simulations of El Niño Southern Oscillation with and without an active Indain Ocean, J. Climate, 8, 3-14, 1995.

Neelin, J. D., D. S. Battisti, A. C. Hirst, F.-F. Jin, Y. Wakata, T. Yamagata, and S. E. Zebiak, ENSO theory, J. Geophys. Res., 103(C7), 14,26114,290, 1998.

Penland, C., and P. D. Sardeshmukh, The optimal growth of tropical sea surface temperature anomalies, J. Climate, 12, 1999-2024, 1995.

Schneider, E. K., Z. X. Zhu, B. S. Giese, B. H. Huang, B. P. Kirtman, J. Shukla, and J. A. Carton, Annual cycle and ENSO in a coupled ocean-atmosphere general circulation model, Mon. Weather Rev., 125, 680-702, 1997.

Schopf, P. S., and M. J. Suarez, Vacillations in a coupled ocean-atmosphere model, J. Atmos. Sci., 45, 549-566, 1988.

Smith, N. R., The BMRC ocean thermal analysis system, Aust. Meteor. Mag., 44, 93-110, 1995a.

Smith, N. R., An improved system for tropical ocean sub-surface temperature analyses, J. Atmos. Oceanic Technol., 12, 850-870, 1995 b.

Suarez, M. J., and P. S. Schopf, A delayed action oscillator for ENSO, J. Atmos. Sci., 45, 3283-3287, 1988.

Thompson, C. J., and D. S. Battisti, A linear stochastic model of ENSO. Part II: Analysis, J. Climate, 14, 445-466, 2001.

Vimont, D. J., D. S. Battisti, and A. C. Hirst, Footprinting: A seasonal connection between the tropics and mid-latitudes, Geophys. Res. Lett., 28, 3923-3926, 2001.

Vimont, D. J., D. S. Battisti, and A. C. Hirst, Pacific interannual and interdecadal equatorial variability in a 1000-yr simulation of the CSIRO coupled general circulation model, J. Climate, 6, 160-178, 2002.

Weisberg, R. H., and C. Wang, Slow variability in the equatorial westcentral Pacific in relation to ENSO, J. Climate, 10, 1998-2017, 1997.

Wyrtki, K., El Niño - The dynamic response of the equatorial Pacific Ocean to atmospheric forcing, J. Phys. Oceanogr., 5, 572-584, 1975.

Wyrtki, K., Water displacements in the Pacific and the genesis of El Niño cycles, J. Geophys. Res., 90, 7129-7132, 1985.

Zhang, R. H., and L. M. Rothstein, Role of off-equatorial subsurface anomalies in initiating the 1991-1992 El Niño as revealed by the NCEP ocean reanalysis data, J. Geophys. Res., 105(C3), 6327-6339, 2000.

W. S. Kessler, NOAA/Pacific Marine Environmental Laboratory, 7600 Sand Point Way NE, Seattle, WA 98115, USA. (kessler@pmel.noaa.gov) 